\title{
ON X-RAY RADIATION OF THE QUIET SUN
}

\author{
By S. L. Mandelshtam \\ (P. N. Lebedev Physical Institute of the U. S. S. R. Academy of Sciences).
}

REsUmé. - On discute les conditions de production de rayons $X$ solaires. La comparaison des calculs récents avec les observations confirme l'hypothèse de l'origine thermique. Dans la région $\lambda<15 \AA$ du spectre solaire, la contribution principale est due aux émissions free-bound des électrons et des ions du carbone, de l'azote, de l'oxygène et d'autres éléments.

L'émission $X$ du Soleil a deux composantes ; l'une à peu près constante due à l'émission des régions non perturbées de la couronne, l'autre, à variations lentes, provient des régions coronales actives.

ABstraot. - The conditions of production of the solar $X$ rays are briefly discussed. The comparison of the results of recent calculations and experimental measurements supports the assumption of a thermal origin of the $X$ ray radiation. In the "tail" of the solar spectrum below $15 \AA$, the main contribution comes from the free-bound radiation of electrons and ions of carbon, nitrogen, oxygen and other elements.

The solar $X$ ray radiation consist of $a$ " quasi-stable" component, produced in undisturbed coronal regions and $a$ " slowly varying" component generated in the active regions of the corona.

Резюме. - Кратко расматриваются условия генерации рентгеновского излучения в солнечной короне. Сопаставление результатов вычислений с экспериментальными данными подтверждает гипотезу о термическом характере рентгеновского излучения спокойного солнца. В области спектра $\lambda<15 \AA$ основной вклад дает свободно- связанное излучение электронов и ионов углерода, кислерода, азота и других элементов.

Рентгеновское излучение солнца состоит из гвазипостоянной компоненты, генерируемой невозмущенными областями короны и "медленноменяюшейся компоненты " генерируемой активныим обла. стями короны.

At present a rather considerable experimental material concerning solar $\mathrm{X}$-ray radiation has been acquired, and analysis of the generation conditions of this emission is of great interest. In this paper the results of studying this problem for the quiet Sun in the region of the "tail " of the solar spectrum - below $20 \AA$ are briefly discussed [1].

$\mathrm{X}$-ray photographs of the Sun made by FrIEDMAN et al. [2], TOUSEY [3] and by ZHITNIK et al. [4] have shown that the major contribution to solar X-ray emission is made by regions of the solar corona situated above Ca plages and coincide with regions of enhanced radio emission in the decimetre range. It is nearby to associate them with so-called "permanent condensations" after WALDMEIER which, according to optical observations, have an enhanced electron density and temperature as compared with the rest of the corona [5].

Most investigators assume that the quiet Sun's $\mathrm{X}$-ray radiation is of thermal origin, i.e., is due to the interaction of electrons having Maxwellian energy distribution with the ions of the coronal plasma. However, assumptions made on the electron density and the temperature of regions ma- king the major contribution to emission are very different.

The first calculations of thermal X-ray emission of the Sun were carried out by ELwERT [6], [7]. ELWERT arrives at the conclusion that there is a satisfactory agreement between calculated and experimental data, in particular, for the absolute magnitude of the $\mathrm{X}$-ray flux below $20 \AA$, proceeding from the temperature of the corona $\mathrm{T}_{e} \approx 1,5 \cdot 10^{6} \mathrm{oK}$, the integral of the square of the electron density after BAUMBACH

$$
y=\int \mathrm{N}_{e}^{2} d v=3.210^{4 \theta},
$$

and taking into account possible small fluctuations of the electron density of about 1 to $2\left({ }^{1}\right)$.

Comparison of the calculations of the X-ray flux below $10 \AA$ made by Ferisow [13] with our experimental measurements has led to the conclu-

(1) ELWERT directly compares the calculated photon flux in the ranges of $2-8$ and $8-18 \AA$ with the number of pulses recorded in these regions by photon counters according to Friedman's measurements [8]. However, the efficiency of the photon counters in these experiments was much less than unity; the recorded photon flux was by one-two orders of magnitude larger than that cited by ELwERT in Table I [7]. 
sion that emitting regions occupied some hundredths parts of the corona's volume, have a temperature of 2 to $3.10^{6} \mathrm{oK}$ and the electron density several times higher than the average one [9].

In a paper by Pounds et al. [10] the results of measuring the $X$-ray flux in the range of 7-11 $\AA$ are compared with ELwERT's calculations. The authors have come to the conclusion that emission is in the main due to " hot nuclei " - sporadic condensations having the temperature of up to $5.10^{6} \mathrm{oK}$ and existing for several hours.

WhIte [11] who measured the emission flux in the spectral region below $10 \AA$ has come to the conclusion that experimental data agree with calculated data if the temperature of emitting regions is assumed to be $2.8-3 \cdot 10^{6} \mathrm{oK}$ and

$$
y=\int \mathrm{N}_{e}^{2} d v=(12-55) \cdot 10^{4 \theta} ;
$$

White assumes that the flux from lines is 10-30 times higher than that of the continuous spectrum.

SHKLOvSKY [12] has first used experimental values of $y=\int \mathrm{N}_{e}^{2} d v$, taken from measurements of the Sun's radio emission at a wavelength of $10.7 \mathrm{~cm}$ and concluded that, for $y=6.10^{49}$ for low solar activity, the theoretical value of the emission flux agrees well with the experimental value of about $1.10^{-4} \mathrm{erg} / \mathrm{cm}^{2} . \mathrm{s}$ in the region below $10 \AA$, if one assumes the usual temperature of the corona 1.5.106 oK. However, this conclusion is based on an over-estimation of the value of the emission flux in lines.

Thus, at present, there is great uncertainty in estimates of $\mathrm{T}_{e}$ and $\mathrm{N}_{e}$ of the coronal regions making the major contribution to $\mathrm{X}$-ray radiation and the relative role of line and continuum emission. It seems reasonable to go on with the analysis of this problem using more precise theoretical values of the emission flux and by comparing it with the actual experimental results for various conditions of solar activity.

We have extended the calculations of the coronal emission flux made earlier [13] up to $20 \AA$ taking in to account bremsstrahlung, recombination and line emissions of the ions of the corona. While calculating the degree of ionization of atoms in the corona we have assumed that photorecombination is the main process of recombinations ; at the present time it is not still clear to what extent the process or two-electron recombination indicated by SEATON and BURGESS [14] may change the results.
For ionization and excitation cross-sections ELWERT's [6] and VAINSHTEIN's [15] approximated values were used. At present we are carrying out calculations of these cross-sections in the BoRNCoulomb approximation. While calculating lines flux the population of upper levels of lines due to electron impact and recombination was taken into account as well as $\mathrm{X}$-rays characteristic lines. The values of the abundance of elements used by us are listed in Table I [16], [17].

\section{TABLE I}

VALUES OF SOlar abUndaNCES USED IN THIS PAPHR :

$$
\delta=\frac{\mathrm{N}_{\mathrm{z}}}{\mathrm{N}_{\mathrm{H}}}
$$

\begin{tabular}{|c|c|}
\hline ELEMENT & ABUNDANCE \\
\hline $\mathrm{H}$ & 1 \\
\hline $\mathrm{He}$ & $2 \quad 10^{-1}$ \\
\hline $\mathrm{C}$ & $5,2510^{-4}$ \\
\hline $\mathrm{N}$ & $9,5 \quad 10^{-5}$ \\
\hline 0 & $9,1 \quad 10^{-4}$ \\
\hline $\mathrm{Ne}$ & $8 \quad 10^{-5}$ \\
\hline $\mathrm{Na}$ & $1,9910^{-6}$ \\
\hline $\mathrm{Mg}$ & $2,5 \quad 10^{-5}$ \\
\hline $\mathrm{Al}$ & $1,5810^{-6}$ \\
\hline $\mathrm{Si}$ & $3,1610^{-5}$ \\
\hline $\mathrm{S}$ & $1,9910^{-5}$ \\
\hline $\mathbf{K}$ & $5,01 \quad 10^{-8}$ \\
\hline Cia & $1,4110^{-6}$ \\
\hline $\mathrm{Fe}$ & $3,71 \quad 10^{-6}$ \\
\hline $\mathrm{Ni}$ & $8,1310^{-7}$ \\
\hline
\end{tabular}

The results of calculating the emission flux near

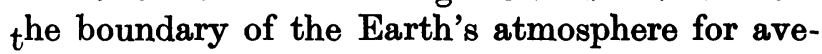
$r$ age model of the corona

$$
\bar{y}=\int \mathrm{N}_{e}^{2} d v=3,210^{49},
$$

are given in Table II. It follows from the Table that in the region of the spectrum below $15 \AA$ the main contribution is made by recombination emission of electrons on " heavy" ions. Figure 1 shows the contributions $\mathrm{E}_{f f}, \mathrm{E}_{f o}, \mathrm{E}_{\mathrm{L}}$ as example for $\mathrm{T}_{e}=2.10^{6} \mathrm{oK}$. The predominant role of recombination emission in the region $\lambda<20 \AA$ is due to the small number of lines in the interval under consideration. In the longer wavelength region, already at $\mathrm{T}_{e} \approx 2.10^{6} \mathrm{oK}$, the contribution of lines becomes essential.

For a substantiated comparison of calculated 


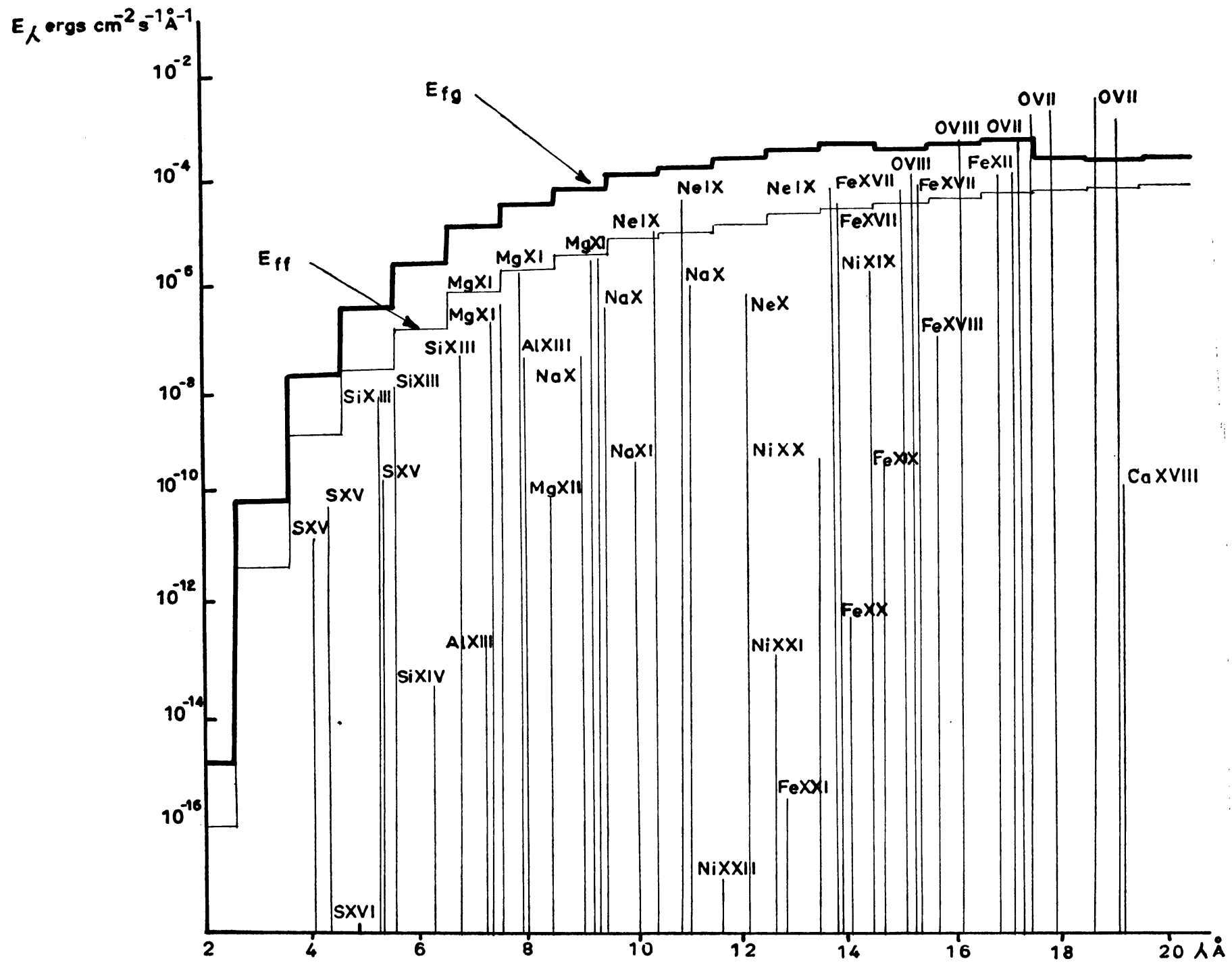

Fra. 1. - The energy of bremsstrahlung $\left(\mathrm{E}_{f f}\right)$, recombination $\left(\mathrm{E} f_{g}\right)$ and line emission $\left(\mathrm{E}_{\mathrm{L}}\right)$ in the region of the spectrum $2.20 \AA$ for $\mathrm{T} e=2.10^{6} \mathrm{~K}$.

and experimental data of the X-ray flux one should know the distribution of the $y^{(\mathrm{K})}=\int_{\mathrm{K}} N_{e}^{2} d v$ (measure of emissivity) and temperature $\mathrm{T}_{e}^{(\mathrm{K})}$ of the corona over the solar disc.

To determine the distribution of the $y^{(\mathrm{K})}$, we have made use of Stanford University radiospectroheliograms which give the distribution of brightness temperature $T^{B}$ at a wavelength $9,1 \mathrm{~cm}$ along the solar disc with resolution $3^{\prime}\left(^{1}\right)$ [18].

(1) At present, radiospectroheliograms on $10 \mathrm{~cm}$ are obtained once per day. At the same time, it is known that the $\mathrm{X}$-ray flux, as well as the distribution of radio brightness along the solar disc, sometimes noticeably varies for a few hours. The absence of simultaneous $\mathrm{X}$-ray and radio observations hinders a detailed comparison of calculations with the experiment although it does not change the forthcoming conclusions.
The required value of $\mathrm{y}^{(\mathrm{K})}$ of some region $(\mathrm{K})$ on the disc is connected with $\mathrm{T}_{(\mathrm{K})}^{\mathrm{B}}$ by the expression [12]

$$
\begin{aligned}
y^{(\mathrm{K})} & =\int_{\mathrm{K}} \mathrm{N}_{e}^{2} d v=0,710^{67}\left(\frac{\mathrm{T}_{e}^{(\mathrm{K})}}{\mathrm{l}}\right)^{1 / 2} \mathrm{~F}_{\nu}^{(\mathrm{K})}, \\
\mathrm{F}_{\nu}^{(\mathrm{K})} & =\mathrm{F}_{\vee} \frac{\int_{\mathrm{K}} \mathrm{T}_{\mathrm{B}} d s}{\mathrm{~T}_{0}}
\end{aligned}
$$

where $y^{(\mathrm{K})}=\int_{\mathrm{K}} \mathrm{N}_{e}^{2} d v$ is taken over the region under consideration, $\mathrm{T}_{e}^{(\mathrm{K})}$ is ts electron temperature, $\mathbf{F}^{(\mathrm{K})}$ is the radio emission flux from the region $\left(K^{)}\right), F \vee$ is the total radio flux from the entire disc. $\mathrm{T}_{\mathrm{O}}$ is $\int \mathrm{T}_{\mathrm{B}} d s$ taken over the entire disc and its values are given in radiospectroheliograms. 
Spectral Energy Distribution in the Re

\begin{tabular}{|c|c|c|c|c|c|c|c|c|c|c|}
\hline \multirow[b]{2}{*}{$\lambda(\AA)$} & \multicolumn{4}{|c|}{$\mathrm{T}=10^{6} \mathrm{o} \mathrm{K}$} & \multicolumn{4}{|c|}{$\mathrm{T}=1,5 \cdot 10^{6} \mathrm{oK}$} & \multicolumn{2}{|c|}{$\mathrm{T}=2.10^{6} \mathrm{o} \mathrm{K}$} \\
\hline & $E_{t f}$ & $\mathrm{E}_{\mathrm{fg}}$ & $\mathrm{E}_{\mathbf{L}}$ & $\mathbf{E} \lambda$ & $E_{f f}$ & $\mathrm{E}_{\mathrm{fg}}$ & $\mathrm{E}_{\mathbf{L}}$ & $E \lambda$ & $\mathrm{E}_{\mathrm{ff}}$ & $E_{f g}$ \\
\hline- & - & - & - & - & - & - & - & - & - & - \\
\hline 2 & $3,98.10^{-82}$ & $1,15.10^{-30}$ & & $1,18.10^{-30}$ & $6,92 \cdot 10^{-22}$ & $1,34.10^{-20}$ & & $141.10^{-20}$ & $1.10^{1-8}$ & $1,6.10^{-15}$ \\
\hline 3 & $4,47.10^{-22}$ & $1,29.10^{-20}$ & & $1,33 \cdot 10^{-20}$ & $2,45 \cdot 10^{-15}$ & $4,75.10^{-14}$ & & 5. $10^{-14}$ & $7,1.10^{-12}$ & $1,14.10^{-1}$ \\
\hline 4 & $3,16.10^{-17}$ & $9,08 \cdot 10^{-16}$ & & $9,4.10^{-16}$ & $4,36.10^{-12}$ & $8,46 \cdot 10^{-11}$ & & $8,9.10^{-11}$ & $1,78.10^{-9}$ & $2,86 \cdot 10^{-8}$ \\
\hline 5 & $2,82.10^{-14}$ & $8,1.10^{-13}$ & $1,1.10^{-14}$ & $8,49 \cdot 10^{-13}$ & $2,82 \cdot 10^{-10}$ & $5,48.10^{-9}$ & $5,3.10^{-10}$ & $6,29 \cdot 10^{-9}$ & $3,16 \cdot 10^{-8}$ & $5,08 \cdot 10^{-7}$ \\
\hline 6 & $2,51 \cdot 10^{-12}$ & $7,21 \cdot 10^{-11}$ & & $7,46.10^{-11}$ & $4,9.10^{-9}$ & $9,51 \cdot 10^{-\varepsilon}$ & & $1,0.10^{-7}$ & $2,1.10^{-7}$ & $3,37 \cdot 10^{-7}$ \\
\hline 7 & $4,47 \cdot 10^{-11}$ & $1,29 \cdot 10^{-8}$ & $8: 7.10^{-11}$ & $1,42 \cdot 10^{-8}$ & $3.10-^{8}$ & $5,83 \cdot 10^{-7}$ & $3,34.10^{-8}$ & $6,46 \cdot 10^{-7}$ & $1.10^{-6}$ & $1.64 .10^{-5}$ \\
\hline 8 & $5.10^{-10}$ & $1,43 \cdot 10^{-8}$ & $1,74.10^{-10}$ & $1,5 \cdot 10^{-8}$ & $1,4.10^{-7}$ & $2,72.10^{-6}$ & $6,5.10^{-8}$ & $2,92 \cdot 10^{-6}$ & $2,5.10^{-6}$ & $3,99 \cdot 10^{-5}$ \\
\hline 9 & $2,5.10^{-9}$ & $7,17.10^{-8}$ & $5,74.10^{-10}$ & $7,48 \cdot 10^{-8}$ & $4.4 .10^{-7}$ & $8,56 \cdot 10^{-6}$ & $2,14.10^{-7}$ & $9,16 \cdot 10^{-6}$ & $5.10^{-6}$ & $7,97.10^{-5}$ \\
\hline 10 & $1.10^{-8}$ & $2,87 \cdot 10^{-7}$ & $8,2.10^{-8}$ & $3,79 \cdot 10^{-7}$ & $1.10^{-6}$ & $1,94.10^{-5}$ & $3,08 \cdot 10^{-6}$ & $2,35 \cdot 10^{-5}$ & $1.10^{-5}$ & $1,59.10^{-4}$ \\
\hline 11 & $2,51 \cdot 10^{-8}$ & $7,1.10^{-7}$ & $2,48 \cdot 10^{-\mathrm{a}}$ & $9,83.10^{-}$ & $2,24.10^{-6}$ & $4,25 \cdot 10^{-6}$ & $9,25 \cdot 10^{-5}$ & $5,39 \cdot 10^{-6}$ & $1,26.10^{-5}$ & $1,94 \cdot 10^{-4}$ \\
\hline 12 & $6,3.10^{-8}$ & $1,79.10^{-6}$ & & $1,85 \cdot 10^{-6}$ & $3,24.10^{-6}$ & $6,15 \cdot 10^{-5}$ & $9,2.10^{-8}$ & $6,46 \cdot 10^{-5}$ & $1,78 \cdot 10^{-5}$ & $2,74 \cdot 10^{-4}$ \\
\hline 13 & $1,26.10^{-7}$ & $3,57 \cdot 10^{-6}$ & & $3,7.10^{-6}$ & $5.10^{-6}$ & $1,95.10^{-4}$ & & $1,0.10 \mathrm{~N}^{4}$ & $2,82.10^{-5}$ & $4,35 \cdot 10^{-5}$ \\
\hline 14 & $2,24 \cdot 10^{-7}$ & $6,34 \cdot 10^{-6}$ & $4,16 \cdot 10^{-7}$ & $6,98 \cdot 11^{-6}$ & $7,6.10^{-6}$ & $1,43 \cdot 10^{-4}$ & $1,66 \cdot 10^{-5}$ & $1,60 \cdot 10^{-4}$ & $3,55 \cdot 10^{-5}$ & $5,47 \cdot 10^{-4}$ \\
\hline 15 & $5.10^{-7}$ & $1,41 \cdot 10^{-5}$ & $1,84.10^{-8}$ & $1,46.10^{-5}$ & $1.10^{-5}$ & $1,75.10^{-4}$ & $3,92 \cdot 10^{-6}$ & $1,89.10^{-4}$ & $4,47.10^{-5}$ & $4,43 \cdot 10^{-4}$ \\
\hline 16 & $7,9.10^{-7}$ & $2,23 \cdot 10^{-5}$ & $3,3.10^{-7}$ & $2,34.16^{-5}$ & $1,41 \cdot 10^{-5}$ & $2,48.10^{-4}$ & $7,9.10^{-5}$ & $3,41.10^{-4}$ & $5,62 \cdot 10^{-5}$ & $5,59 \cdot 10^{-4}$ \\
\hline 17 & $1,26.10^{-6}$ & $3,55 \cdot 10^{-5}$ & $1,2.10^{-4}$ & $1,57 \cdot 10^{-4}$ & $1,58 \cdot 10^{-5}$ & $2,77.10^{-4}$ & $1,01 \cdot 10^{-3}$ & $1,30.10^{-3}$ & $7,1.10^{-5}$ & $7,04 \cdot 10^{-4}$ \\
\hline 18 & $1,58.10^{-6}$ & $2,99 \cdot 10^{-5}$ & $2,14.10{ }^{4}$ & $2,45.10^{-4}$ & $2,19 \cdot 10^{-5}$ & $1,97 \cdot 10^{-4}$ & $1,84 \cdot 10^{-3}$ & $2,06 \cdot 10^{-3}$ & $7,94 \cdot 10^{-5}$ & $3,23 \cdot 10^{-4}$ \\
\hline 19 & $2,52 \cdot 10^{-6}$ & $5,04.10^{-5}$ & $3,10 \cdot 10^{-4}$ & $3,52 \cdot 10^{-4}$ & $2,4.10^{-5}$ & $1,94.10^{-4}$ & $2,82 \cdot 10^{-3}$ & $3,03 \cdot 10^{-5}$ & $8,91 \cdot 10^{-5}$ & $2,86 \cdot 10^{-4}$ \\
\hline 20 & $2,86 \cdot 10^{-6}$ & $5,29 \cdot 10^{-5}$ & & $5,57.10^{-5}$ & $2,82 \cdot 10^{-5}$ & $2,28.10^{-4}$ & & $2,56 \cdot 10^{-4}$ & $1.10^{-4}$ & $3,02.10^{-4}$ \\
\hline
\end{tabular}

TABLE III

\begin{tabular}{|c|c|c|c|c|}
\hline & $\begin{array}{l}\text { UNDISTURBED } \\
\text { REGIONS }\end{array}$ & \multicolumn{3}{|c|}{$\begin{array}{c}\text { ACTIVE REGIONS OF THE CORONA } \\
\text { (CONDENSATIONS) }\end{array}$} \\
\hline $\begin{array}{l}\mathrm{T}_{\mathrm{B}}\left(10^{3} \mathrm{oK}\right) \\
\mathrm{T}_{e}\left(10^{6} \mathrm{oK}\right)\end{array}$ & $\mathrm{T}_{\mathbf{B}}<30$ & $30 \leqslant \underset{1.5}{T_{B}}<60$ & $60 \leqslant T_{1.75}<150$ & $\begin{array}{l}T_{B} \geqslant 150 \\
2.5\end{array}$ \\
\hline
\end{tabular}

TAB

Calculated and Experimental Values of the

\begin{tabular}{|c|c|c|c|c|c|c|c|}
\hline \multirow{2}{*}{$\begin{array}{c}\text { BRIGHTNESS } \\
\text { TEMPERATURE } \\
\mathrm{T}_{\mathrm{B}}\left(10^{3} \text { oK }\right)\end{array}$} & \multirow{2}{*}{$\begin{array}{c}\text { ELECTRON } \\
\text { TEMPERATURE } \\
\mathrm{T}_{e}\left(10^{6} \text { oK) }\right.\end{array}$} & \multicolumn{2}{|c|}{$\begin{array}{c}\text { FEBR. } 15,1961 \\
\text { (THE TOTAL PHASE } \\
\text { OF THE ECLIPSE) }\end{array}$} & \multicolumn{2}{|c|}{ APRIL 6, 1962} & \multicolumn{2}{|c|}{ APRIL 27, 1962} \\
\hline & & $y\left(10^{48}\right)$ & $E_{2-10 \AA}$ & $y\left(10^{48}\right)$ & $E_{3-11} \AA$ & $y\left(10^{48}\right)$ & $\mathrm{E}_{7-11 \AA}$ \\
\hline- & - & - & - & - & - & - & - \\
\hline $\mathrm{T}_{\mathrm{B}} \geqslant 150$ & 2,5 & 3,7 & $9,4 \cdot 10^{-5}$ & 0 & 0 & 27 & $1,1.10^{-4}$ \\
\hline $60 \leqslant \mathrm{~T}_{\mathrm{B}}<150$ & 1,75 & 5,0 & $1,5 \cdot 10^{-5}$ & 1,4 & $8,7 \cdot 10^{-6}$ & 15 & $9,3 \cdot 10^{-5}$ \\
\hline $30 \leqslant \mathrm{~T}_{\mathrm{B}}<60$ & 1,5 & 3,5 & $3,5 \cdot 10^{-5}$ & 26 & $6,1.10^{-5}$ & 17 & $4,6 \cdot 10^{-5}$ \\
\hline $\mathrm{T}_{\mathrm{B}}<30$ & 1,0 & 5,7 & $7.10^{-8}$ & 32 & $1,3 \cdot 10^{-6}$ & 28 & $1,1 \cdot 10^{-6}$ \\
\hline The entire disc & - & - & $1,1.10^{-4}$ & 一 & $7,1.10^{-5}$ & 一 & $1,2.10^{-3}$ \\
\hline Experimental flux & - & - & $8.10^{-5}$ & - & $1,8 \cdot 10^{-4}$ & - & $1,2.10^{-3}$ \\
\hline
\end{tabular}


LE II

GION 2-20 $\AA E_{\lambda}-\operatorname{erg} . c^{-2} . s^{-1} . \AA^{-1}$

\begin{tabular}{|c|c|c|c|c|c|c|c|c|c|}
\hline \multirow[b]{2}{*}{$\mathrm{E}_{\mathbf{L}}$} & \multicolumn{6}{|c|}{$\mathrm{T}=3.10^{6} \circ \mathrm{K}$} & \multicolumn{3}{|c|}{$\mathrm{T}^{\prime}=4.10^{6} \mathrm{oK}$} \\
\hline & $\mathrm{E} \lambda$ & $E_{f f}$ & $E_{f g}$ & $\mathrm{E}_{\mathbf{L}}$ & $\mathrm{E} \lambda$ & $F_{p f}$ & $R_{f g}$ & $\mathbf{E}_{\mathbf{L}}$ & $E \lambda$ \\
\hline \multirow[t]{3}{*}{-} & - & - & - & - & - & -- & - & - & - \\
\hline & $1,7.10^{-18}$ & $1,28.10{ }^{11}$ & $1,13.10^{-10}$ & & $1,26.10^{-10}$ & $3,95.10^{-9}$ & $1,77.10^{-8}$ & & $2,16 \cdot 10^{-8}$ \\
\hline & $1,21.10^{-10}$ & $1,44.10^{-8}$ & $1,28.10^{-7}$ & & $1,42.10^{-7}$ & $6,72.10^{-7}$ & $3,01.10^{-6}$ & & $3,68.10^{-6}$ \\
\hline $1.10^{-10}$ & $3,04.10^{-8}$ & $4,57.10^{-7}$ & $4,04.10^{-6}$ & $1,9.10^{-8}$ & $4,52.10^{-6}$ & $1.10^{-5}$ & $4,47.10^{-5}$ & $5,7.10^{-7}$ & $5,53 \cdot 10^{-5}$ \\
\hline \multirow[t]{2}{*}{$3,57.10^{-8}$} & $5,76.10^{-7}$ & $3,54.10^{-6}$ & $3,14.10^{-5}$ & $1,72.10^{-6}$ & $3,66.10^{-5}$ & $3.10^{-5}$ & $1,33.10^{-4}$ & $1,3 \cdot 10^{-5}$ & $1,76.10^{-5}$ \\
\hline & $3,58.10^{-6}$ & $1,24.10^{-5}$ & $1,09.10^{-5}$ & & $1,21.10^{-4}$ & $7.10^{-6}$ & $3,03.10^{-4}$ & & $3,73.10^{-44}$ \\
\hline $4,6.10^{-7}$ & $1,75.10^{-5}$ & $2,5.10^{-5}$ & $2,19.10^{-4}$ & $1,14.10^{-5}$ & $2,55.10^{-4}$ & $1,13.10^{-4}$ & $4,91.10^{-4}$ & $4,5.10^{-5}$ & $6,49 \cdot 10^{-4}$ \\
\hline $7,8.10^{-7}$ & $4,32.10^{-5}$ & $4,45.10^{-5}$ & $3,86.10^{-4}$ & $1,63.10^{-5}$ & $4,46.10^{-4}$ & $1,4.10^{-4}$ & $6,02.10^{-4}$ & $4,9.10^{-5}$ & $7,91.10^{-4}$ \\
\hline $2,57.10^{-6}$ & $8,73.10^{-5}$ & $7,56.10^{-5}$ & $6,54.10^{-4}$ & $5,34.10^{-5}$ & $8,08.10^{-4}$ & $1,98.10^{-4}$ & $8,32.10^{-4}$ & $1,48.10^{-4}$ & $1,18.10^{-3}$ \\
\hline $1,82.10^{-5}$ & $1,87.10^{-4}$ & $8,9.10^{-5}$ & $7,71 \cdot 10^{-4}$ & $8,92.10^{-5}$ & $9,49 \cdot 10^{-4}$ & $2,5.10^{-4}$ & $1,03.10^{-3}$ & $1,28.10^{-4}$ & $1,41.10^{-34}$ \\
\hline $5,5.10^{-5}$ & $2,62.10^{-4}$ & $1,12.10^{-4}$ & $9,18 \cdot 10^{-4}$ & $2,68.10^{-4}$ & $1,30.10^{-4}$ & $3,3.10^{-4}$ & $1,27.10^{-3}$ & $3,84.10^{--4}$ & $1,98.10^{-3}$ \\
\hline \multirow[t]{2}{*}{$1,0.10^{-6}$} & $2,94.10^{-4}$ & $1,25.10^{-4}$ & $1,02.10^{-3}$ & $9,0.10^{-5}$ & $1,22.10^{-3}$ & $3,38.10^{-4}$ & $1,3.10^{-3}$ & $6,1.10^{-4}$ & $2,25.10^{-3}$ \\
\hline & $4,63.10^{-4}$ & $1,58.10^{-4}$ & $1,3.10^{-3}$ & & $1,46.10^{-3}$ & $3,45.10^{-4}$ & $1,33 \cdot 10^{-3}$ & $1,0.10^{-6}$ & $1,67.10^{-3}$ \\
\hline $1,46.10^{-4}$ & $7,28.10^{-4}$ & $1,77 \cdot 10^{-4}$ & $1,45.10^{-3}$ & $4,64 \cdot 10^{-4}$ & $2,08 \cdot 10^{-3}$ & $3,52.10^{-1}$ & $1,36.10^{-3}$ & $6,6.10^{-4}$ & $2,37.10^{-8}$ \\
\hline $1,76.10^{-4}$ & $6,64.10^{-4}$ & $1,99.10^{-4}$ & $4,99.10^{-4}$ & $5,9.10^{-6}$ & $7,57 \cdot 10^{-4}$ & $3,52.10^{-4}$ & $3,23.10^{-4}$ & $1,05.10^{-4}$ & $7,81 \cdot 10^{-4}$ \\
\hline $6,3.10^{-4}$ & $1,24.10^{-3}$ & $2,23.10^{-4}$ & $5,54.10^{-4}$ & $2,05 \cdot 10^{-3}$ & $2,82 \cdot 10^{-3}$ & $3,52.10^{-4}$ & $3,24.10^{-4}$ & $1,6.10^{-3}$ & $2,27.10^{-4}$ \\
\hline $2,5.10^{-3}$ & $3,27.10^{-3}$ & $2,23.10^{-4}$ & $5,54.10^{-4}$ & $1,25.10^{-3}$ & $2,02 \cdot 10^{-2}$ & $3,52.10^{-4}$ & $3,24.10^{-4}$ & $5,16.10^{-4}$ & $1,19.10^{-8}$ \\
\hline $3,76.10^{-2}$ & $4,16 \cdot 10^{-3}$ & $2,51 \cdot 10^{-4}$ & $3,31.10^{-4}$ & $2,04.10^{-8}$ & $2,62.10^{-3}$ & $3,52.10^{-4}$ & $2,43 \cdot 10^{-4}$ & $6,56.10^{-4}$ & $1,25 \cdot 10^{-3}$ \\
\hline \multirow[t]{2}{*}{$7,17.10^{-4}$} & $7,55.10^{-8}$ & $2,51.10^{-4}$ & $2,64.10^{-4}$ & $9,06 \cdot 10^{-3}$ & $9,57 \cdot 10^{-3}$ & $3,52.10^{-4}$ & $2,43.10^{-4}$ & $5,52.10^{-3}$ & $6,11 \cdot 10^{-3}$ \\
\hline & $4,02 \cdot 10^{-4}$ & $2,51.10^{-4}$ & $2,61.10^{-4}$ & & $5,12 \cdot 10^{-4}$ & $5,52 \cdot 10^{-4}$ & $2,04.10^{-4}$ & & $5,66.10^{-4}$ \\
\hline
\end{tabular}

For distribution $\mathrm{T}_{e}^{(\mathrm{K})}$ over the solar disc at present there are no systematic experimental data. Therefore, we have assumed for our calculations that there is some correlation between the electron density and electron temperature of active regionscondensations.

For numerical calculations we have taken the following tentative values $\mathbf{T}_{e}$, characterizing the values of the electron density by the brightness radio temperature $\mathrm{T}_{\mathrm{B}}$ (Tabl. III).

Using the $T_{e}^{(\mathrm{K})}$ and $\mathrm{y}^{(\mathrm{K})}$ values thus obtained, we have compared experimental and calculated values of the X-ray flux for six measurements made on February 15, 1962 ; April 6, 1962 ; April 27, 1962 ; May 3, 1962 ; October 18, 1962, and October 22, 1962. We have used the measurements carried

LE IV

Solar X-RAY FlUXes $\mathrm{E}_{\Delta \lambda}$ IN ERG/CM ${ }^{2} \mathrm{~S}$

MAY 3,1962

\begin{tabular}{ccc}
$\left.y 10^{48}\right)$ & $\mathrm{E}_{7-11 \AA}$ & $y\left(10^{48}\right)$ \\
-22 & $-\overline{10}$ & - \\
14 & $8,9.10^{-4}$ & 2,5 \\
29 & $8,8.10^{-5}$ & 17 \\
19 & $6,8.10^{-5}$ & 24 \\
- & $7,6.10^{-7}$ & 30 \\
- & $1,0.10^{-3}$ & - \\
\hline
\end{tabular}

Ocт. 18, 1962

$\mathrm{E}_{2-10} \AA$
$6,4 \cdot 10^{-5}$
$5,2 \cdot 10^{-5}$
$2,4 \cdot 10^{-5}$
$3,8 \cdot 10^{-7}$
$1,4 \cdot 10^{-4}$
$1,7 \cdot 10^{-4}$

$\mathrm{E}_{8-18 \AA}$
$-10^{-4}$
$5,1.1 .10^{-3}$
$1,2.10^{-3}$
$1,1.10^{-4}$
$2,8.10^{-3}$
$2,3.10^{-3}$

$y\left(10^{48}\right)$
-
6,9
8,3
25
31
-
-

Ост. 22, 1962

$$
\begin{gathered}
E_{2-10 \AA} \\
- \\
1,8 \cdot 10^{-4} \\
2,6 \cdot 10^{-5} \\
2,5.10^{-5} \\
3,9.10^{-7} \\
2,3.10^{-4} \\
4,7.10^{-4}
\end{gathered}
$$

$E_{8}-18 Y \AA$

$1,4 \cdot 10^{-3}$

$6.10^{-4}$

$1,0.10^{-3}$

$1,2 \cdot 10^{-4}$

$3,1.10^{-3}$

$3,6 \cdot 10^{-3}$ 


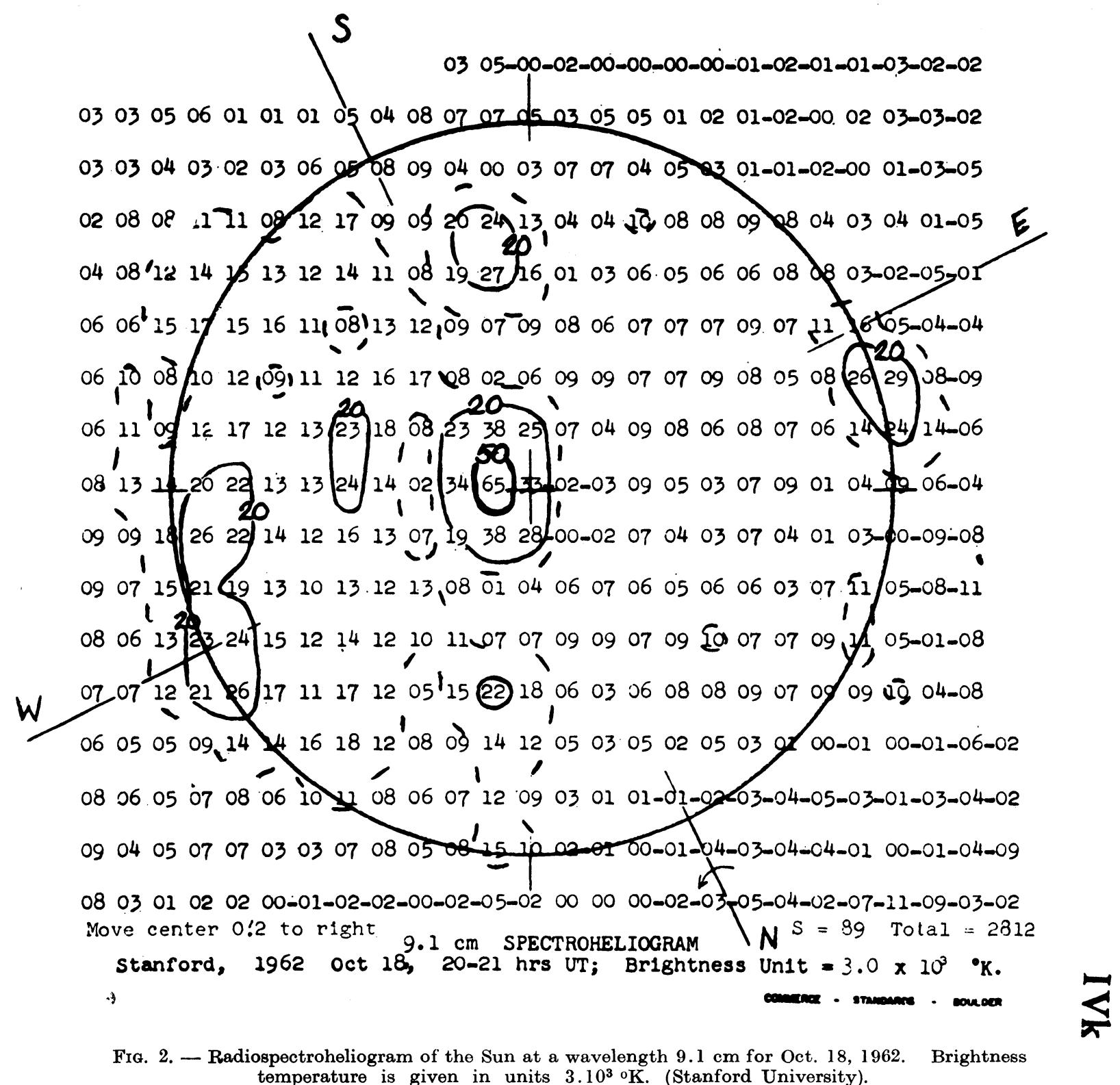

out by us in the range 2-10 $\AA$ by means of photon counters with Be-window, and in the range 8-18 $\AA$ by means of photon counters with $\mathrm{Al}$-windows [9], [19], data by Pounds et al. obtained in the interval 7-11 $\AA$ by means of a proportional counter with the Be-window [10] and WHITE's data obtained by means of an ionization chamber with the Be-window [11].

The day of February 15, 1961 is interesting by the fact that measurements were carried out at the moment of the total solar eclipse. At this moment only two centres of activity near the western and eastern limb of the disc remained uncovered by the Moon. The day of April 6, 1962, is characterized by a very low X-ray flux. Other days are characterized by a very different level of solar activity. In Figure 2 a radiospectroheliogram for October 18, 1962 , is given as an example.

The calculations of $\mathrm{X}$-ray fluxes were performed as follows. For each of the days mentioned above, all the points on the radiospectroheliogram of the given day were subdivided into four groups. Three groups characterize active regions of the corona with brightness temperature $\mathrm{T}_{\mathrm{B}} \geqslant 150.10^{3} \mathrm{oK}, 150.10^{3}>\mathrm{T}_{\mathrm{B}} \geqslant 60.10^{3} \mathrm{oK}, 60$. $10^{3}>\mathrm{T}_{\mathrm{B}} \geqslant 30.10^{3}$ oK and the fourth group characterizes undisturbed regions of the corona $\mathrm{T}_{\mathrm{B}}<30.10^{3} \mathrm{oK}$. For each of these groups of 


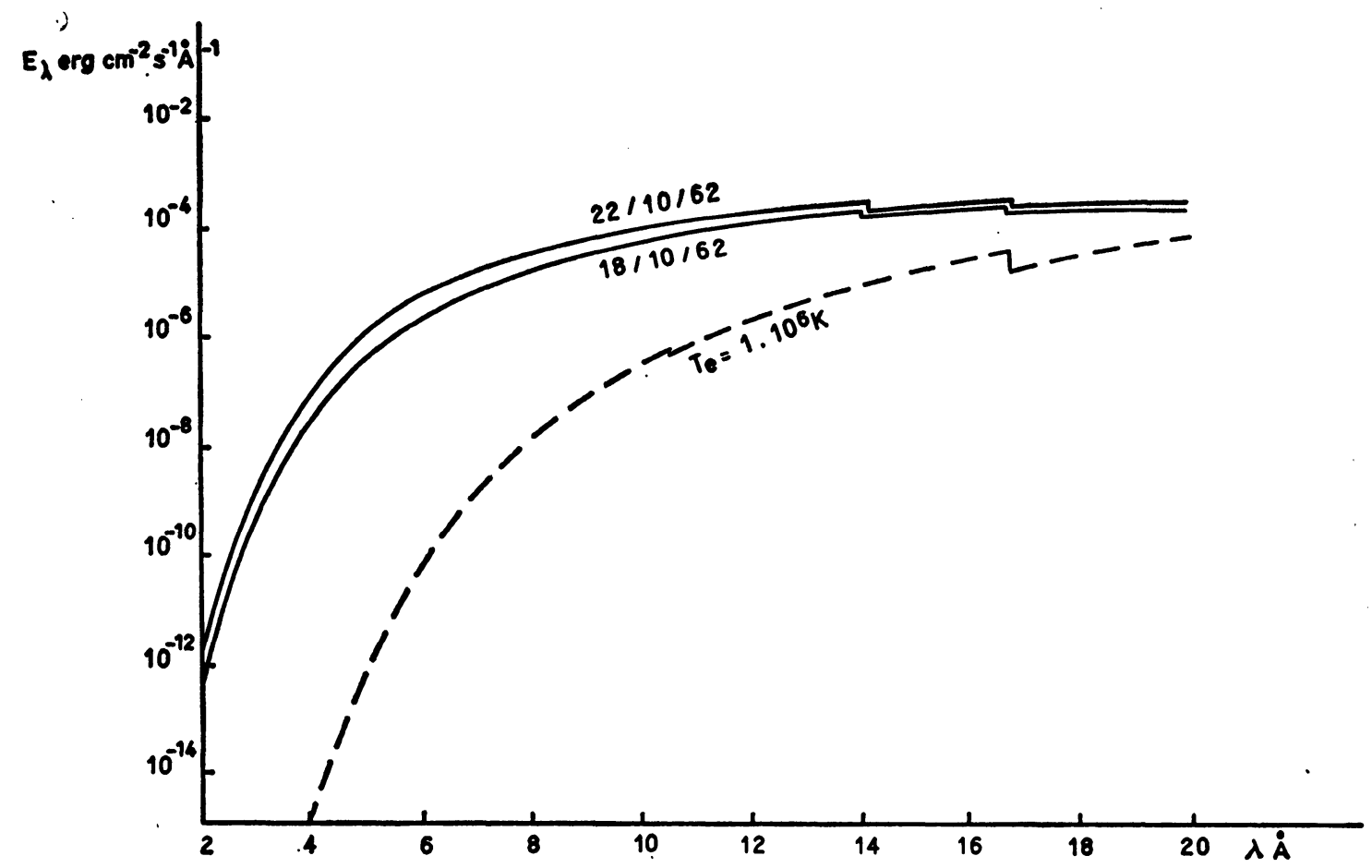

Fig. 3. - Energy distribution near the "tail" of the solar spectrum for Oct. 18, 1962, and Oct. $22,1962$.

points the value of $\mathrm{y}^{(\mathbf{k})}$ was calculated, and the value of the $T_{e}^{(\mathbf{x})}$ was ascribed to this group of points by means of Table III. According to these values of $y^{(\mathbf{K})}$ and $T_{e}^{(\mathbf{K})}$ the calculated value of the X-ray flux was determined from Table II for this group of points; then, these fluxes were summed for all four groups, giving the $\mathrm{X}$-ray flux for the entire Sun.

The results of calculations and experimental values of $X$-ray fluxes are summarized in Table IV.

The Table shows that calculated and experimental values of the $\mathrm{X}$-ray flux agree sufficiently well. Discrepancy by 2-3 times should not confuse us. The accuracy of the ionization and excitation cross-sections used lies within these limits, uncertainty is caused by imprecise knowledge of the abundance of elements in the corona ; and at last, experimental absolute values of $\mathrm{X}$-rays fluxes now hardly can be more precise. On the other hand, the temperature Table III, which forms the basis of the calculations, is no doubt a very rough and tentative model for the correlation between the electron density and the temperature of condensations. However it should be pointed out that calculated values of $X$-rays fluxes cannot be made to agree with experimental data if we change essentially the temperature values $-\mathrm{T}_{e}$ corresponding to different values of $\mathrm{T}_{\mathrm{B}}$ taken by us in this Table. For instance, if one ascribes the value $\mathrm{T}_{e} \approx 1.5 .10^{6} \mathrm{oK}$ to the whole corona and a temperature greater by $5.10^{4} \mathrm{oK}$ to active regions as SHKLovsky does, the calculated values of the $\mathrm{X}$-rays flux in the interval 2-10 $\AA$ turns to be 3-10 times lower than experimental ones. In a similar way there is no agreement with the whole experimental material if, for instance, one takes a rougher model in which a temperature $\mathrm{T}_{e} \approx(2.5-3) \cdot 10^{6} \mathrm{oK}$ is ascribed to condensation regions with $\mathrm{T}_{\mathrm{B}} \geqslant 150.10^{3} \mathrm{oK}$, and $\mathrm{T}_{e} \approx(1-15) .10^{6}$ oK to the rest of the corona, etc....

Figure 3 presents the energy distribution near the "tail" of the solar spectrum which follows from the above calculations for October 18 and October 22, 1962. Emission from the undisturbed corona for both days is indicated by a dotted curve and corresponds to $\mathrm{T}_{e}=1.10^{6}$ and $y=3,1.10^{49}$.

On the basis of the calculations, the conclusion may be drawn that apparently the $\mathrm{X}$-ray emission from the quiet Sun (in the absence of flares) is thermal. It is formed from a "quasi-stable" component corresponding to the undisturbed corona on which " hotter" emission is superimposed from active regions of the corona - " the slowly varying " component [11]. This portion of 


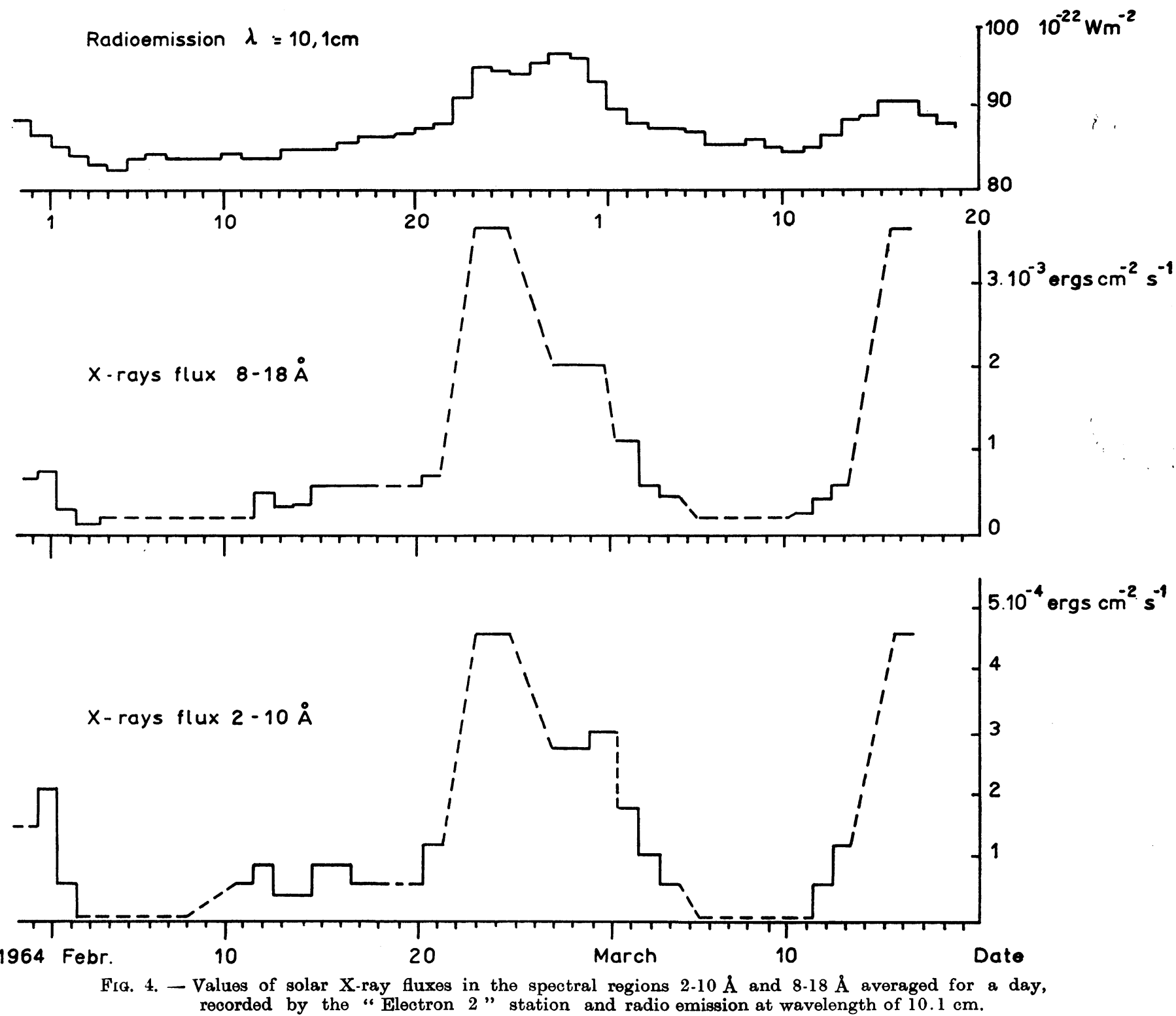

emission can vary strongly depending on the number and parameters of active regions ( ${ }^{1}$ ). Figure 4 presents, as an illustration, values of the $X$-ray flux averaged during a day in the range 2-10 $\AA$ and 8-18 $\AA$ according to recordings made by means of the "Electron 2 " station from February 30, 1964, to March 16, 1964 ; for comparison the values of the radio emission flux at a wavelength of $10.1 \mathrm{~cm}$ are given. It should be pointed out that one cannot expect a complete

(1) The comparison of the photographs of the SUN made by TOUSEY all [3] and ZHITNIK and al [4], fortunately separated by exactly one solar revolution, shows that the regions of enhanced X-ray emission are retained on the Sun during this time. correlation between the values of $\mathrm{X}$-ray and radio emission fluxes since the radio emission flux is determined by the magnitude $\sum_{\mathrm{K}} y^{(\mathbf{K})}\left(\mathrm{T}_{e}^{(\mathbf{K})}\right)--^{1 / 2}$ i.e. it very weakly depends on the temperature, while the $\mathrm{X}$-ray flux is determined by the magnitude

$$
\sum_{\mathbf{K}} y^{(\mathbf{K})} e^{-\frac{h v}{k \mathbf{T}_{e}^{(\mathbf{K})}}}
$$

i.e. depends on the temperature very strongly. Therefore both undisturbed and disturbed regions make a comparable contribution to radio emission while a contribution to $\mathrm{X}$-ray emission is made only by disturbed regions with high temperatures. 
It must also be noted, that the used values of $y^{(k)}$ have been obtained by means of a radiotelescope with the resolution $3^{\prime} \times 3^{\prime}$, while the dimensions of emission sources with high $\mathbf{T}_{e}$ can be lower as, in particular, believed by FrIEDMAN [2].

To further confirm the above conclusions, we plan to scan the solar disc for a sufficiently long time in two spectral intervals 2-10 and 8-18 $\AA$ which will enable us to independently and simultaneously determine $N_{e}$ and $T_{e}$ and to obtain a map of the distribution of $\mathrm{N}_{e}$ and $\mathrm{T}_{e}$ over the solar disc.

\section{REFERENCES}

[1] Manderlahtam S. L., Prokudina N. S., Tindo I. P., Fetisov E. P., Kosmicheskije Issledovanija (in press).

[2] Blake R. L., Chubb T. A., Friedman H., UNzioker A. E., 1963, Ap. J., 137, 3.

[3] Tousey R., 1964, Quarterly Journal at the Royal Astronomical soc. 5, 123.

[4] Zhitrin I. A., Krotov V. V. Malyavkin L P., MaNdmLShtam S. L., Kosmicheskije Issledovanija, 2, 920.

[5] WaLdMeiter M., 1963, Z. Astrophys., 58, 571964.

[6] Elwhet G., 1954, Z. Naturforsch., 9a, 637.

[7] Elwhrt G., 1961, J. Geophys. Res., 66, 391.

[8] Chubb T. A., Friedman H., Krepuin R. W., 1960, Space Research, I. North-Holland Publ. Co.

[9] Mandhlshtam S., Tindo I., Voron'ko Yu., Vasimyev B., Shuryain A., Fetisov E., XIII Astronaut. Congress, Varna, Bulgaria. IX, 1962. Springer Verlag, 1964.
[10] Bowen P. I., Pounds K. A., Whlmore A. P. Norman K., Santrord P. W., 1964 Proc. Roy, Soc., A, 281, 538.

[11] Wнттв W. A., Space Research, IV. NorthHolland Publ. Co., Amsterdam 1964.

[12] SHkLowsky I. S., 1964, Astronomicheskij Journal, XLI, 676.

[13] Frrisov E. P., 1963, Kosmicheskije Issledovanija, $1,209$.

[14] BUrams A., 1964, Ap. J., 139, 776 ; Seaton M., 1964, Planetary Space Sci., 12, 55.

[15] Varnstein L. A., 1961, Optics $i$ Spetroskopy, 11, 301.

[16] Potтasoh S. R., 1963, Ap. J., 187, 945.

[17] Goldberg L., Müller E., Aller L., 1960, $A p . J .$, suppl., 5, No 45 .

[18] U. S. Department of Commerce. N. B. S. Bull. C. R. P. L.-F. No. 213-214-219 Part B.

[19] Tindo I. P., Shuryan A. I., Kosmicheskjei Issledovanija, in press. 